\title{
Quando a literatura fala à história: a ficção de Barbosa Lessa e a memória pública no Rio Grande do Sul
}

\author{
When Literature Addresses History: the Fiction of Barbosa Lessa and \\ Public Memory in Rio Grande do Sul, Brazil
}

\section{Jocelito Zalla}

jocelito.zalla@ufrgs.br

Professor

Colégio de Aplicação

Universidade Federal do Rio Grande do Sul

Av. Bento Gonçalves, 9500 - Prédio 43815 - Agronomia

91501-970 - Porto Alegre - RS

Brasil

\section{Resumo}

O objetivo deste trabalho é analisar as intervenções de Luiz Carlos Barbosa Lessa, escritor, folclorista e militante fundador do movimento tradicionalista gaúcho, no debate público rio-grandense pela literatura de imaginação. Para tanto, parte-se de um episódio que agitou a produção letrada local na década de 1950, o chamado "caso Sepé", em torno do qual foi ponderada a conveniência ou inviabilidade de incorporar a experiência missioneira guarani na narração do passado gaúcho. Busca-se, portanto, não somente averiguar as posições do autor no debate, mas avaliar as possibilidades e escolhas formais de confronto, em especial a escrita literária como contraponto ao discurso histórico. A tomada de posição de Lessa sobre a questão indígena leva a críticas mais amplas ao modelo dominante de memória histórica no estado, orientando seu projeto literário para criações até então pouco comuns, como a figuração de grupos e segmentos tidos como marginais (indígenas, negros, mulheres), além da reafirmação do caráter popular do gaúcho rio-grandense.

\section{Palavras-chave}

Fiç̧ão; Historiografia sul-rio-grandense; Regionalismo.

\begin{abstract}
The objective of this work is to analyze the interventions of Luiz Carlos Barbosa Lessa (writer, folklorist and activist-founder of the Gaucho Traditionalist Movement) in the public debate of Rio Grande do Sul, using the imagination-literature. We start from the episode that shook the local literate production in the 1950s, the so-called "Sepé polemic", on the merits or the impracticability of incorporating the experience of the Guarani Misiones in the narratives of the Gaucho past. I seek, therefore, not only to ascertain the positions of the author, but to evaluate the possibilities and formal choices for confrontation, in particular by examining literary writing as a counterpoint to the historical discourse. Lessa's standing on the Indigenous issue leads to deeper criticisms of the dominant model of historical memory in the state of Rio Grande do Sul, guiding his literary project towards unusual creations, such as the portrayal of groups and segments previously seen as marginal ones (Indigenous groups, Afro-Brazilians, women), and a reaffirmation of the popular character of the Gaucho from Rio Grande do Sul.
\end{abstract}

\section{Keywords}

Fiction; South Rio Grande Historiography; Regionalism.

Recebido em: 26/7/2014

Aprovado em: 15/10/2014 
Sabemos que a incorporação da história das Missões Jesuítas ao patrimônio cultural do Rio Grande do Sul foi polêmica, gerando debates acalorados. Boa parte dos intelectuais ligados ao Instituto Histórico e Geográfico do Rio Grande do Sul (IHGRS) era, nas décadas de vinte a sessenta, pelo menos, refratária à ideia de que a história das reduções indígenas sob o controle jesuíta e comando do império espanhol pudesse ser agregada à história do Rio Grande luso e brasileiro. De posição contrária, um grupo marginal de eruditos inspirava-se na literatura gauchesca e em material folclórico para ampliar os motivos da historiografia regional. Tal polarização se acirrou em 1955, quando uma comissão do Instituto, composta por Afonso Guerreiro Lima, Othelo Rosa e Moysés Vellinho, deu parecer negativo à criação de monumento em homenagem aos duzentos anos da morte do líder guarani Sepé Tiaraju, que se completariam em fevereiro de 1956.

O então folclorista Luiz Carlos Barbosa Lessa entrou na arena de disputa, redigindo significativo artigo sobre o tema. Sua resposta mais contundente, todavia, veio em 1958, com a publicação do livro de contos $O$ boi das aspas de ouro, em que traçava um inventário mítico da história sul-rio-grandense. Mais do que isso, parece que a perspectiva literária que passa a ser construída pelo autor, além de motivos e problematizações constantes em sua obra, tem na disputa um ponto fulcral. O objetivo deste trabalho é, portanto, analisar as posições e os meios de expressão empregados por Barbosa Lessa no episódio citado e nas contendas mais profundas de memória pública no Rio Grande do Sul. 38 Quais são as articulações entre seu projeto folclórico e o novo projeto ficcional? Quais são os usos e as funções da literatura de imaginação em batalhas de memória? Enfim, o que Barbosa Lessa podia dizer pela ficção que seria vetado pela escrita da história?

\section{A memória histórica oficial e um novo escritor}

Há cerca de vinte anos, Ieda Gutfreind (1992) apresentou uma interessante tese sobre a historiografia sul-rio-grandense tradicional: uma divisão entre duas matrizes historiográfico-ideológicas pautaria as posições dos eruditos locais. A primeira, chamada lusitana, enalteceria o papel do estado no cenário nacional, sua vocação militar pela defesa da fronteira do país no sul do continente e a predominância do branco luso na composição étnica da população. A segunda, dita platina, ainda que reivindicasse a mesma relação de inserção no contexto luso-brasileiro, reconheceria a existência de fluxos econômicos e culturais com os países da bacia do Prata. Os recentes trabalhos de Letícia Borges Nedel ${ }^{1}$ sobre o regionalismo gaúcho oferecem uma via alternativa de acesso às lutas de representação no contexto citado, mas, em alguma medida, neste trabalho, conciliável com as reflexões de Gutfreind. ${ }^{2}$ Para Nedel, as disputas intelectuais

\footnotetext{
${ }^{1}$ Ver NEDEL 2000; 2004; 2005.

2 Antes de se tornar escritor de ficção, Barbosa Lessa atuou em comissões de folclore, participou da fundação do primeiro Centro de Tradições Gaúchas, o "35" CTG, foi tradutor e repórter da Revista do Globo. Em todos os círculos profissionais e grupos de que participava, travou relações com historiadores, folcloristas e escritores regionalistas. Antes de iniciar a pesquisa de campo que originaria o Manual de Danças Tradicionais (1956), produzido em coautoria com João Carlos Paixão Cortes, foi orientado pelo folclorista Dante de Laytano, seu
} 
não se davam apenas em função da definição do lugar político do Rio Grande na construção do Brasil, mas pela forma como os autores negociavam suas identidades sociais e profissionais por meio desse debate. O problema que Nedel se propõe em seu trabalho não é determinar as contribuições ideológicas dos intelectuais locais, mas pensar sobre os reflexos de seus compromissos nos campos literário e acadêmico da época, estruturados por uma "patrulha do particularismo" que visava à projeção política do estado, mas restringia tais campos a uma escala regional. Entre as divergências e questões em jogo, podem-se citar os assuntos narrados, os heróis celebrados - e sua legitimidade para a rememoração histórica -, os tipos de fonte utilizados e o diálogo com o discurso literário. Nedel mostra que, a partir da década de 1920, dois "registros" de memória pública foram elaborados no debate regionalista local: naquele que também comportava, em historiografia, o que Gutfreind e Lessa qualificaram como adesão ao lusitanismo/lusitanofilia, o foco de atenção estava dirigido à geopolítica, à história das "marchas e contramarchas de Portugal e Espanha sobre o Rio Grande de São Pedro"; no segundo tipo, que poderíamos associar à "matriz platina", o privilégio era dado à identificação de um sujeito folk, "associado ao mundo rural, à condição de rebaixamento social e à intimidade com o meio físico" (Cf. GUTFREIND apud NEDEL 2004, p. 358) - daí a aproximação com a gauchesca argentina e uruguaia.

No final dos anos 1940, uma série de fatores, como a constituição da Comissão Gaúcha de Folclore (CEF), braço da Comissão Nacional de Folclore (CNFL), o advento do movimento tradicionalista gaúcho e a reavaliação geral do discurso regionalista, punham em dia a antiga tensão. Nesse contexto, a questão indígena reaparecia na pauta intelectual, ${ }^{3}$ extrapolando o âmbito das publicações oficiais do IHGRS ou as monografias de seus membros, em altercações que movimentavam os jornais locais e, como veremos, reanimariam a produção literária conhecida como "gauchesca".

Em 1947, o jovem Luiz Carlos Lessa, ${ }^{4}$ estudante do Colégio Júlio de Castilhos (o "Julinho") e colaborador esporádico da Revista do Globo, publicou nesse veículo reportagem sobre a vida de um grupo de tropeiros da região sul do estado. Num misto de texto jornalístico e ficção regionalista, o autor relacionava aqueles trabalhadores rurais com o gaudério mítico do século XVIII, o "centauro da pampa", que inspirara a literatura local precedente. Na reconstrução e atualização discursivas do modelo romântico de camponês sul-

professor de História no Colégio Júlio de Castilhos, a ler toda a produção local possível sobre a figura do gaúcho, o que incluía história, folclore e literatura. Portanto, busco tanto em Gutfreind quanto em Nedel possibilidades de construção de perguntas à sua obra que permitam, na análise empreendida, reconstruir os quadros de referência e os diálogos de um autor socializado intelectualmente num contexto erudito geral que se encontrava sob a égide do regionalismo, mas que também era leitor atento da produção historiográfica em particular. Como mostrado por Nedel, a oposição platinismo/lusitanismo é apenas uma dentre outras antíteses acionadas nos esquemas de pensamento dos intelectuais locais (como passadismo/modernismo, regionalista/ não regionalista). Como veremos ao longo do artigo, mais do que outras, tal oposição tem grande importância para a produção literária de Lessa, configurando a crítica historiográfica que realiza por meio da ficção.

3 Como exemplo da atualidade da questão, vale lembrar que Erico Verissimo, então maior expressão da literatura local, no primeiro tomo da saga O Tempo e o Vento, publicado em 1949, conciliava simbolicamente a tradição guarani com a história de ocupação lusitana pelo enlace entre Pedro Missioneiro e Ana Terra.

${ }^{4}$ Nosso autor adotou o sobrenome materno Barbosa em 1953, quando assumiu a coluna "Tradição" do jornal Diário de Notícias de Porto Alegre. 
-rio-grandense, Lessa deixava clara sua adesão à interpretação que via o gaúcho como desenvolvimento sócio-racial dos povos autóctones: "O pampa, sem obstáculos e sem limites, convidava o gaúcho a um viajar sem fim. E nasceram os andarengos, os carreteiros, os tropeiros - herdeiros natos do sangue nômade dos índios minuanos e charrua" (LESSA 1947, p. 28-29). A filiação indígena é, assim, estendida ao gaúcho gentílico do século XX, ou seja, a todo habitante do Rio Grande do Sul, visto como descendente direto do camponês de antanho. 0 jovem jornalista revivia em seu texto uma antiga tese histórica e literária que perpassava a parca historiografia local do século XIX, como em Alcides Lima e Alfredo Varela, ou a obra de escritores como Simões Lopes Neto, mas que fora relegada, como dito, a um segundo plano pela historiografia tradicional.

Naquele mesmo ano, nosso personagem ingressou no Departamento de Tradições Gaúchas do Julinho, durante as atividades da primeira Ronda Gaúcha, mais tarde batizada Ronda Crioula, em homenagem ao dia 20 de setembro, data comemorativa da eclosão da Revolução Farroupilha, de 1835. A entidade se tornou o embrião para a fundação, em 1948, do "35" Centro de Tradições Gaúchas, modelo, por sua vez, para as demais sociedades cívicas que passaram a se espalhar pelo Rio Grande. Como é sabido, juntamente com João Carlos D'Ávila Paixão Côrtes, Lessa se tornou um dos principais teóricos do movimento tradicionalista. O jornalista se valeu, então, de sua inserção (ainda incipiente) no meio intelectual para divulgar o novo gauchismo, passando a vincular seu projeto literário em embrião ao projeto coletivo tradicionalista. Internamente, HO disputou os rumos e as diretrizes do movimento, propulsando o novo processo de invenção de tradições ao encontro do gaúcho pampiano, ${ }^{5}$ de extração popular, em detrimento da elite lusa, nobre e militar, louvada pela memória histórica oficial. Dessa forma, ele se constituía em uma "autoridade" política e intelectual do tradicionalismo, elaborando e arbitrando sobre o legítimo e o correto em tradição folclórica. Seus textos, assim como suas composições musicais e coreográficas, devem ser compreendidos como partícipes do esforço de configuração do ideário tradicionalista. No entanto, em sentido inverso, com a repercussão e o peso adquirido pela adesão geral crescente e a simpatia inicial da erudição local, ${ }^{6}$ o movimento se tornava, para Lessa, uma instância de consagração e legitimação intelectual, o que lhe permitia atingir públicos mais amplos e disputar as perspectivas do regionalismo então em redefinição. ${ }^{7}$

\footnotetext{
${ }^{5}$ Durante a construção da entidade, havia uma divisão entre dois grupos de perspectivas divergentes: o primeiro buscava uma sociedade de tipo fechado, ao estilo maçom, com um número máximo de 35 membros; o segundo, liderado por Barbosa Lessa e Paixão Côrtes, pretendia um clube gaúcho aberto a todo interessado, independentemente de ter um vínculo direto com o campo. Composto, em grande parte, por oficiais da Brigada Militar, a primeira facção previa ainda um projeto de celebração voltado ao panteão de heróis da historiografia tradicional, oriundo da elite estancieira e militar.

6 Desde cedo, os tradicionalistas pioneiros buscaram atrair para suas fileiras os intelectuais regionalistas de renome por meio de convites para palestras e pela cessão de cargos honoríficos na estrutura do "35". A estratégia, inicialmente, surtiu efeito. O segundo boletim informativo do Centro, de 1950, por exemplo, foi custeado por Moysés Vellinho e J. P. Coelho de Souza, entre outros. Poucos se integrariam, entretanto, ao quadro social da entidade. Coelho de Souza, então deputado federal, aceitaria o convite para ser "posteiro" no Rio de Janeiro. Apenas Manoelito de Ornellas e Walter Spalding se tornariam membros efetivos da sociedade e participariam, inclusive, dos primeiros congressos tradicionalistas, apresentando teses e coordenando suas principais mesas de discussão.

7 Segundo Odaci Coradini, nos anos 1940 e 1950, "o regionalismo passou por redefinições e sua versão mais 'heróica' perdeu a legitimidade na cultura erudita, o que não exclui a legitimidade dos temas 'regionais'ou
} 
Seu primeiro livro, publicado em 1953, retornava, de forma indireta, à questão indígena: História do chimarrão traçava um panorama da bebida "típica" desde seu cultivo primitivo e ritual pelas populações nativas até a exploração econômica pelos conquistadores europeus. Se o autor já havia afirmado a ligação racial do sul-rio-grandense com o indígena, o chimarrão era o elo cultural com o povo guarani. No momento em que os CTG buscavam reviver nas cidades os costumes de uma figura rural que para muitos estaria extinta ou em vias de extinção, Lessa escrevia o seguinte: "Só o chimarrão permanece como tradição fundamental do gaúcho, elevando-se ao patamar de um símbolo imorredouro e inconfundível". Um jangadeiro sem sua jangada perde sua caracterização, nos diz o autor, assim como o gaúcho sem o seu cavalo tende a perder sua identidade. Todavia, continua, mesmo "sem o cavalo e sem o galpão, o gaúcho readquire instantaneamente sua tipicidade no momento em que leva aos lábios a bomba do chimarrão" (BARBOSA LESSA 1986, p. 65). O gentílico é novamente unido ao gaudério social e mítico, produto, por sua vez, do encontro entre as culturas autóctones e europeias.

Ambos os textos citados, correspondentes aos períodos pré e pós-movimento tradicionalista, permitem-nos apreender a posição de Barbosa Lessa sobre a filiação racial e cultural (também) indígena do sul-rio-grandense. De certa forma, o debate em torno da figura de Sepé Tiaraju, corregedor guarani de São Miguel das Missões, vinculou a questão indígena, como dito, à possibilidade de admitir a tradição missioneira na história sul-rio-grandense. Em 1955, o IHGRS foi acionado pelo então governador do estado, Ildo Meneghetti, para verificar a validade da proposta do major João Carlos Nobre da Veiga de erigir um monumento em homenagem ao bicentenário da morte de Sepé. A comissão do Instituto, liderada por Moysés Vellinho, deu parecer negativo, o que causou reação de intelectuais como Mansueto Bernardi, ex-diretor da Revista do Globo, e o grupo de historiadores folcloristas ligados a Dante de Daytano e à Comissão Estadual de Folclore. Como mostrado por Letícia Nedel, o episódio originou debates e protestos que ganharam as páginas dos jornais durante muito tempo e ecoaram na produção artística tradicionalista e nativista. ${ }^{8}$

\section{O caso Sepé e os intelectuais em confronto}

O texto do parecer, publicado no suplemento cultural do jornal Correio do Povo em novembro de 1955, opera com uma distinção entre o Sepé mítico e o Sepé histórico: o primeiro é visto com simpatia, considerado, no plano das lendas, "um dos elementos que configuram e enriquecem nosso patrimônio cultural" (LIMA; ROSA; VELLINHO 1980, p. 140); o segundo é o ponto da discórdia, já que a validação do monumento deveria ser dada em termos de

'locais' ou, ainda, algo como o 'regionalismo social' por oposição ao 'regionalismo heróico'. Portanto, mais do que ser regionalista, o que está em questão são os critérios de definição desse regionalismo, cujas alterações podem acentuar determinados critérios de diferenciação, mais 'naturais', mais literários, ou mais políticos" (CORADINI 2003, p. 134).

${ }^{8}$ No artigo citado, a autora também analisa uma payada (gênero situado entre a música e a poesia), gravada em 1981, de Noel Guarany, "compositor e intérprete que, além de reivindicar a herança missioneira para os habitantes do estado, retrata o herói civilizador gaúcho como tipo humano originário (autóctone) de um território mais antigo que o Brasil, não só contíguo ao Prata, mas integrado a ele" (NEDEL 2004, p. 349). 
brasilidade. Em referência a ensaio publicado por Mansueto Bernardi na década de $1920^{9}$ e republicado pelo próprio Vellinho na quinta edição de sua revista Província de São Pedro, ${ }^{10}$ em 1946, a Comissão proferia: "Quando lemos que Sepé foi 'o primeiro caudilho rio-grandense' a nós mesmos perguntamos que noção ele poderia ter do Rio Grande do Sul..." (LIMA; ROSA; VELLINHO 1980, p. 141). Politicamente, a reação ao Tratado de Madri só poderia ter em vista a integridade territorial da Província do Paraguai e, por extensão, a defesa da Coroa espanhola, daí a conclusão negativa: "não só é inaceitável o 'brasileirismo' de Sepé, como ainda não é admissível encará-lo como uma expressão do sentimento, das tendências, dos interesses, da alma coletiva, enfim, do povo gaúcho, que se estava formando ao signo da colonização portuguesa" (LIMA; ROSA; VELLINHO 1980, p. 142).

A resposta de Bernardi foi publicada no Correio do Povo no ano seguinte, às vésperas da data tida como da morte do líder guarani, 07 de fevereiro. Entre os argumentos desse autor, encontramos o revide historiográfico: a luta indígena não teria sido resposta ao tratado em si, mas à transmigração forçada tanto por espanhóis quanto por portugueses, e mesmo pelos jesuítas, daí a falácia do vínculo do personagem com o império hispânico. Mais interessante para nossa questão é o raciocínio racial de Bernardi:

Sepé Tiaraju é muito mais gaúcho e, por conseguinte, muito mais brasileiro - não no sentido moderno e político do vocábulo, mas no sentido autóctone e racial - do que os próprios membros da Comissão de História, os quais descendem de lusitanos aportados ao Continente de São Pedro, quando muito há 230 anos, ao passo que ele provinha de uma "nação" aqui radicada "desde o tempo do dilúvio" [...] (BERNARDI 1980 , p. 41).

O contra-ataque do escritor seguia à risca a refutação, por sua incitação, do Padre Luís Gonzaga Jaeger, que, durante a sessão extraordinária de 18 de outubro de 1955, havia aprovado "com restrições" o parecer da Comissão. No encontro seguinte, em 25 de outubro, esse historiador surpreendia os colegas com sua Defesa do intrépido gaúcho, o Capitão José Tiaraju, o lendário S. Sepé, em que a redenção do corregedor guarani se dava pelo apego à terra natal, origem espacial do futuro Rio Grande: "Coloquemo-nos uns instantes na realidade do índio missioneiro. É que ele tinha um sentido profundamente pronunciado, se não de Pátria - como parecem negá-lo os confrades da Comissão -, mas um apego insuperável à querência, à gleba que os vira nascer" (JAEGER 1980, p. 150). A imprecisão dos sentimentos de nacionalidade entre os gaúchos do século XVIII, compreendidos como grupo sociorracial, invalida o critério de apreciação empregado pela Comissão de História: "O gaúcho, como tal, não

\footnotetext{
9 O texto original, também intitulado $O$ primeiro caudilho rio-grandense, foi elaborado como palestra, ministrada em 1926, a convite de Alcides Maya, no Museu Histórico Júlio de Castilhos.

10 Periódico da Editora Globo voltado aos temas do Sul, dirigido por Moysés Vellinho e que circulou entre os anos de 1945 e 1954. Sobre o programa regionalista da revista, informa Coradini: "Mas fica explícito também que consite numa reação dessa 'elite cultural' às novas condições nas relações centro/periferia - em oposição ao 'centralismo' ou 'padronização cultural' - e, por outro lado, ao antigo regionalismo 'tradicionalista' ou 'saudosista', ou aos 'exclusivismos localistas' em nome dos 'autênticos valores do passado" (CORADINI 2003, p. 136).
} 
tem nacionalidade determinada. Encontramo-lo nas coxilhas rio-grandenses, no gaúcho uruguaio, argentino e paraguaio" (JAEGER 1980, p. 153).

Durante meses a fio, várias personalidades intelectuais e políticas locais se pronunciaram nas páginas dos jornais, defendendo um ou outro dos pontos de vista. Para resumir o apelo e a complexidade da contenda, apontarei suas inflexões no setor mais caro a Barbosa Lessa, o movimento tradicionalista. No livro em que Bernardi compilou seus textos em favor de Sepé, incluindo o parecer oficial do IHGRS (e os pareceres apócrifos que a ele se seguiram), publicado originalmente em 1957 pela Editora Globo, o escritor noticiava que o "35" CTG, como se poderia esperar, manifestara-se contrariamente à decisão do Instituto em ofício dirigido ao governador, assim iniciado:

Sr, Governandor. O "35 Centro de Tradições Gaúchas do Rio Grande do Sul" sente-se no dever de manifestar a V. Excia. sua desaprovação ao parecer emitido pelo Instituto Histórico e Geográfico do Rio Grande do Sul no caso da personalidade histórica do Índio Sepé, em que pese a respeitabilidade daquela nobre instituição (BERNARDI 1980, p. 126).

Contudo, em janeiro de 1956, uma pequena coluna do Correio do Povo transcrevia um ofício da entidade, o qual solicitava ao governador a construção de um monumento em honra aos heróis da "guerra de demarcação", de 1801. Segundo o texto, o Tratado de Madri não teria vigorado de fato na segunda metade do século XVIII, o que teria deixado a população do Continente à mercê de castelhanos e índios missioneiros, que invadiam o território, "saqueando as fazendas, incendiando casas, desacatando famílias". A situação só teria se resolvido quando um grupo de rio-grandenses e paulistas, pouco mais de 60 homens, fez capitular o governador espanhol das Missões, dominando o território. Dessa forma, o Centro indicava um marco diferente para a fundação simbólica do Rio Grande, referente não ao "gaúcho missioneiro", mas aos continentinos e paulistas de origem portuguesa, seguindo a recomendação do parecer do IHGRS:

Não poderemos esquecer os Conquistadores das Missões. Praticando o feito memorável, eles não só acrescentaram um vasto e fértil território ao Brasil, como asseguraram a paz com a República Argentina, criando uma fronteira bem caracterizada pela linha d'água do Rio Uruguai ( $A$ CONQUISTA 1956, p. 8)..$^{11}$

Barbosa Lessa, que, naquele ano, residia na capital paulista, ${ }^{12}$ parece não ter gostado da resolução proposta pelos companheiros de militância. Um manuscrito encontrado em seu acervo pessoal ${ }^{13}$ expõe a opinião de nosso autor sobre o conflito. Surpreendentemente, ele acabava por criticar ambos os grupos

\footnotetext{
${ }^{11}$ Assinaram o documento Cyro Dutra Ferreira, então patrão do "35" e um dos tradicionalistas pioneiros do DTG do Julinho, e Plínio de Moura, "Primeiro Sota-Capataz" (secretário) da entidade.

12 Em 1954, Barbosa Lessa fixou residência em São Paulo para atuar como consultor regionalista da Companhia Cinematográfica Vera Cruz, que estava filmando uma adaptação de Ana Terra, trecho do primeiro tomo da trilogia de Erico Verissimo.

13 O Acervo Barbosa Lessa está sediado (e aberto à pesquisa desde 2002) no Forte Zeca Neto, prédio da Secretaria de Cultura do Município de Camaquã, na zona Sul do estado.
} 
de intelectuais envolvidos no caso, recorrendo a termos muito semelhantes àqueles utilizados conceitualmente por Gutfreind décadas depois:

Há duas correntes intelectuais, no Rio Grande do Sul, que bipartem os estudos históricos: a dos lusitanófilos e a dos hispanófilos. Nessas circunstâncias, somente pode merecer reconhecimento público, na província, o herói que previamente tenha estudado História Universal e optado claramente por uma das duas filiações (BARBOSA LESSA 1956).

Além disso, se Tiaraju tivesse sido um "nobre cavaleiro das côrtes ibéricas", nos diz o escritor, Portugal e Espanha lutariam pela primazia em comemorar festivamente a data de sua morte, e ele "seria então herói espanhol, sob a alegação de ter combatido Portugal, ou herói português, sob a alegação de ter combatido Espanha". Em sua ótica, a recuperação de Sepé seria justa e correta, mas, na contramão da Comissão de História, dever-se-ia justamente à sua força como mito, já que seus feitos teriam sido conduzidos por ideais universais: "Naquele momento, na alma de Tiarajú fervilhavam sentimentos que sobrepairam às correntes históricas, às escolas literárias e mesmo às convenções de nacionalidades: incentivavam-no os sentimentos mais profundos de amor à família, à gleba e à liberdade". A crítica às divergências nacionalistas dos cultores oficiais da memória do Rio Grande é explícita: "Valha Sepé Tiarajú - na época porque passa o nosso mundo - como um símbolo de resistência às patriotadas. Com esse valor, certamente, o herói não merecerá o acatamento daqueles que tomam o pulso da História com medidas da Política Internacional". Canonizado pelo povo, entretanto, Sepé Tiaraju teria a reverência de todos os humildes:

Por isso mesmo, a data de 7 de fevereiro será comemorada com maior grandeza ainda, pois ao invés de agitar-se no fanfarroneio das avenidas, recolher-se-á ao convívio silencioso e amigo de todos os tiarajús que cada homem traz consigo no âmago de sua alma (BARBOSA LESSA 1956).

Apesar da condenação indiscriminada dos motivos de ambos os grupos que se digladiavam no caso, os alvos principais do artigo eram, obviamente, os intelectuais que negavam a reverência ao herói indígena. Em muitos momentos, como no texto de apresentação do Boletim do "35", nosso autor não teve pudor em manifestar seu patriotismo, expresso também no lema da entidade: "Em qualquer chão, sempre gaúcho!" (O 35 1950, p. 1). O patriotismo, no entanto, não deveria ser confundido com as "patriotadas" que cegavam os homens de cultura frente a valores tão nobres como aqueles que Sepé simbolizaria. Entretanto, tal postura "universalista" não pode esconder suas simpatias pela inclusão da memória missioneira ao patrimônio do estado.

\section{Das contendas de memória à literatura de imaginação}

O projeto intelectual de Barbosa Lessa, até então dominado pelo jornalismo e pelo folclore, dialogava com a tradição literária regionalista e com os projetos contemporâneos de literatura e de identidade regional, disputando, como dito, a redefinição do próprio regionalismo. Nesse sentido, um elemento formal 
deve ser avaliado: a natureza dos gêneros discursivos empregados pelos dois registros de memória pública. Além das questões colocadas por cada posição, como apontado por Nedel, a manifestação do discurso folk, desde o começo do século XX, deu-se majoritariamente pelo texto de ficção. Comprometidas com uma perspectiva de "história monumento", as primeiras pesquisas em História no estado fizeram recair sobre os heróis farroupilhas e os tropeiros de origem lusitana o título de "fundadores do Rio Grande". Mesmo a aproximação dessa elite portuguesa com o termo "gaúcho", tornado denominativo de todo o habitante do estado, dava-se de cima para baixo, pela nobilitação do gentílico, ${ }^{14}$ estratégia que permitia desviar dessa disciplina "as complicações implícitas ao predomínio do 'sermo rusticus' comum ao regionalismo da prosa literária" (NEDEL 2005, p. 68). Se é verdade que a oposição também aparecia na literatura, ${ }^{15}$ o privilégio do "gaúcho popular" no conto e no romance regional e o predomínio do herói militar em historiografia estabeleciam uma espécie de divisão discursiva do trabalho de elaboração da memória local.

Se, na segunda metade da década de 1950 , o foco do projeto intelectual de Barbosa Lessa passou a ser a literatura, não podemos negligenciar a afinidade histórica do folclore regional com a ficção como possível constrangimento para alguém, nessa altura, reconhecido pela pesquisa de campo e atuação, para além do movimento tradicionalista, como dito, nas Comissões Gaúcha e Paulista de Folclore. ${ }^{16}$ Após a redação de um livro híbrido, que passava pelo ensaio histórico, pela crônica e por instruções do tipo "manual" para o correto preparo do chimarrão, nosso autor publicou, em 1958, uma coletânea de contos gauchescos. O boi das aspas de ouro é, então, um novo artefato de intervenção nos rumos do tradicionalismo gaúcho, na cena literária, mas também no desenho de um patrimônio cultural etnicamente agregador. Assim, a atualização do mito do gaúcho a cavalo, que servira de modelo à formalização da ritualítisca tradicionalista, também passava pela ampliação dos grupos sociais nele encarnados. Essa avaliação aparece na crítica de Gilda Bittencourt ao livro de Barbosa Lessa, mas a autora não alcança a inovação representada por suas apostas literárias e pelas ideias políticas nelas contidas:

Embora na obra de Lessa haja uma constatação das mudanças da sociedade campeira (como a chegada do colono, do trem e da lavoura) e o conseqüente empobrecimento do gaúcho, e até mesmo o autor aborde

\footnotetext{
${ }_{14} \mathrm{Em}$ virtude da confusão incontornável entre o gaúcho, de significado originalmente pejorativo, e o sul-rio-grandense, no caso da Revolução de 1835, a solução, como mostra Letícia Borges Nedel, seria, justamente, aproximar o primeiro termo da classe social que sustentara o episódio farroupilha; assim, o sentido nobre da palavra, exclusivo aos habitantes do estado brasileiro, seria "[...] uma decorrência da extração social 'superior' das elites locais - ou seja, do papel desempenhado não pela plebe na sustentação do Império, mas pelos representantes legalmente constituídos por um Estado nacional forte e organizado." (NEDEL 2005, p. 68).

15 Mesmo na literatura, os críticos de então identificaram duas vertentes, uma platina e outra sul-rio- grandense, que abordavam de diferentes formas a figura do gaúcho, sendo a segunda mais conservadora em termos estéticos e de linguagem. O exemplo clássico da primeira seria a obra de Alcydes Maia, que mesclava vocabulário e estrutura narrativa erudita com temática popular.

${ }^{16}$ A convite de Dante de Laytano, Barbosa Lessa e Paixão Côrtes ingressaram na CEF em 1950. O acesso às discussões do movimento folclórico brasileiro possibilitou, além do material necessário (como o gravador de voz), a instrumentalização nas técnicas de pesquisa folclórica que fundamentaram a coleta de elementos, entre 1950 e 1952, para a criação das "danças tradicionais gaúchas", difundidas pelo já citado Manual. Com o estabelecimento em São Paulo, Barbosa Lessa passou a frequentar a Comissão Paulista, pela qual empreendeu estudos no interior daquele estado e mesmo viagens à região Norte do país.
} 
uma questão quase ignorada pela gauchesca tradicional - a escravidão nas fazendas -, os textos, em seu conjunto, reproduzem o mesmo modelo de antes, cultuando idênticos valores e expressando a mesma concepção de uma sociedade "fechada", com valores próprios, e refratária a tudo o que vier de fora (BITTENCOURT 1999, p. 32).

Atualizado, ampliado e ressignificado, seu modelo, entretanto, já não é o mesmo da literatura precedente. Joana Bosak de Figueiredo chega a conclusões diametralmente opostas às de Gilda Bittencourt. Para ela, ao tomar como foco de seus escritos o gaúcho empobrecido, Barbosa Lessa teria se "afastado drasticamente" dos mitos do "centauro dos pampas" e do "monarca das coxilhas" (FIGUEIREDO 2006, p. 38). Ambas as posições, no entanto, devem ser matizadas. Como Figueiredo mesmo aponta, a literatura de Barbosa Lessa se configura em um meio-termo na tradição regionalista, ou seja, coloca-se entre (e podemos dizer também contra) o ufanismo e o "disforismo", nos termos da proposição de Cyro Martins, com seu gaúcho a pé, ${ }^{17}$ conciliando o elogio do mito à crítica da realidade. O modelo prescrito por Lessa é diferente porque o autor reconstrói o mito a partir de novos elementos e responde a outro contexto, mas ainda se apropria criativamente dos signos do gauchismo romântico. Nesse processo, o projeto literário de Barbosa Lessa se abre para vozes até então esquecidas ou marginalizadas:

[...] em sua visada ao Rio Grande do Sul, estão presentes o índio, o negro e a mulher como fundadores dessa pequena pátria, tanto quanto o elemento açoriano, o jesuíta, o espanhol, o tropeiro e todo o tipo de figura masculina privilegiada por uma leitura mais tradicional do que seja a formação social sul-rio-grandense (FIGUEIREDO 2006, p. 38).

Dado que o debate sobre o caso Sepé adentrara o ano de 1957, pelo menos, nas páginas dos jornais locais, ${ }^{18}$ o tratamento da questão indígena no novo livro de Barbosa Lessa ainda deve ser compreendido como uma resposta à negação da contribuição missioneira à formação sociorracial e cultural do sul-rio-grandense. O único conto da coletânea que não é apresentado por um narrador personagem, aparentemente identificado com o próprio autor, intitulado $A$ mboi-guaçu de São Miguel, é narrado pela voz de uma mulher missioneira descendente dos povos autóctones. A lenda teria sido contada ao autor (que a teria transcrito da mesma forma) pela mestiça guarani Sebastiana Gonçalves de Oliveira, aos 97 anos de idade (BARBOSA LESSA 1958, p. 38). O que há de mais inovador na literatura regionalista de Barbosa Lessa, como apontado por Joana Bosak de Figueiredo, possivelmente seja a atenção dada ao papel da mulher na formação do caráter regional. "mboi-guaçu" é uma história de resistência, além de indígena, feminina. A voz da velha mestiça apresenta a lenda da "cobra grande" que cercara as ruínas

\footnotetext{
17 Ver MARTINS 1979. Esta oposição será explorada mais adiante.

${ }^{18} \mathrm{Em}$ novembro de 1957, por exemplo, três textos sobre a questão apareceram no suplemento cultural do Correio do Povo: no dia 02, Arthur Ferreira Filho defendia a posição da Comissão de História em artigo de opinião; no dia 09, Eurico Rodrigues chamava, em ensaio, a tese de Bernardi de "fraude histórica"; no dia 23 de novembro, Júlio Sérgio de Castro, lamentava em versos a visão oficial de Sepé, segundo o IHGRS: "Se sobraste na História, ainda cabes num poema".
} 
de São Miguel após a Guerra Guaranítica. Com seus homens mortos nas batalhas, restara às mulheres abrigarem-se, com as crianças, no interior da sala grande da igreja. O mato tomara conta das lavouras e aproximara-se das portas da redução. Com ele, chegou a mboi-guaçu, conhecida outrora apenas pelos relatos daqueles homens que se aventuravam pelo sertão. A cobra grande espantou os tigres e os morcegos que rondavam o lugar, mas, impossibilitada de chegar ao centro da praça devido à barreira aos matagais constituída pelo chão pisado por muita gente, abrigou-se na sala dos sinos, de onde exigia, com seu badalar, a refeição que saciasse sua fome. O barulho ensurdecedor enlouqueceu a primeira mulher que sacrificou seu filho para cessar o martírio. Quando a fome de mboi-guaçú voltava, outra mulher seguia seu exemplo, até que, de tanto se alimentar de carne tenra, a cobra explodiu e deixou as últimas sobreviventes seguirem sua sina em paz. Barbosa Lessa não se furtou de interpretar a lenda. Na apresentação da narrativa, nosso autor relaciona o sacrifício dos filhos à cobra àquele feito para as tropas de guerra:

Se, dentre os leitores, encontrar-se alguém propenso a traçar simbolismos, talvez possa perceber, na história da Mboi-Guaçu, certa correlação com a compreensível angústia que as pobres viúvas guaranis - vítimas da guerra, e desamparadas em sua desdita - por certo sentiam ao entregar seus filhos às forças de recrutamento militar (BARBOSA LESSA 1958, p. 38).

Recolhido/escrito e publicado no calor daquele embate, o conto de Barbosa Lessa indicava pública e claramente sua posição: incluir como parte do repertório de contos "regionais" uma lenda missioneira de matriz indígena significava incorporar à memória oficial aquele pedaço de Rio Grande cuja historicidade fora negada pelos intelectuais do IHGRS. Sendo, ainda, narrada por uma descendente de guaranis e portugueses (uma complacente e significativa concessão dentro da lógica da obra), a história une simbolicamente os dois povos na formação do brasileiro sul-rio-grandense. A relação entre Barbosa Lessa e o grupo de historiadores folcloristas que apoiava Mansueto Bernardi também se dava pela sua opção por uma memória tanto tributária da literatura gauchesca quanto coletora da tradição oral, que, como mostrado por Letícia Nedel,

sugeria uma relativa variação de temas em relação ao repertório clássico da historiografia, sobretudo porque o local ali se fazia representar por um novo sujeito histórico, pelo "guardião" de um passado vivenciado na prática: o "povo", único elemento capaz de revelar o "substrato psíquico" da província (NEDEL 2005, p. 368).

A preocupação com a definição de "povo" e "popular" e com políticas de espectro variado para o suporte do objeto designado por esses termos esteve, como dito, presente na formulação do projeto individual de Barbosa Lessa e na sua perspectiva de projeto tradicionalista, manifestando-se em 1956 na constatação de que as "gentes humildes" não abandonariam o santo Sepé no bicentenário de seu sacrifício. O foco da tradição deveria ser, pois, esse sujeito histórico identificado ao gaúcho campeiro e "simples" e, portanto, mais uma 
vez, oposto ao gaúcho elitista, militarizado e nobilitado pela historiografia. Se este último, entretanto, também aparecerá nos escritos de nosso autor, talvez isso se deva ao seu anseio pela incorporação dos mais variados segmentos da sociedade sul-rio-grandense na atualização do mito. Ainda que o campo intelectual local estivesse pouco especializado, sendo mesmo comum o trânsito de escritores por diversos gêneros discursivos, ${ }^{19}$ naquele momento, em vista do debate em torno da efetividade da herança indígena e missioneira à cultura local, o histórico da literatura de ficção se revelava a Lessa como a melhor possibilidade de expressão textual para tal projeto.

\section{A ampliação do "gaúcho" e a reafirmação do popular}

A tomada de posição frente à questão indígena na memória histórica local dificilmente se manteria sem uma crítica mais profunda ao modelo lusitano, militar, latifundiário e masculino de herói celebrado oficialmente. Incorporar o passado missioneiro e a contribuição indígena à formação do povo gaúcho implicava desenvolver o olhar para outros fatores, étnicos e sociais, há muito tempo discriminados. O boi das aspas de ouro também direcionaria a atenção da história (e da literatura) para o longo e velado preconceito contra o negro no Rio Grande do Sul. Em outro conto do livro, intitulado "Cabos Negros", nosso autor relata a dura vida de escravo nas fazendas de plantação. Junto à crítica da escravidão, encontramos ainda uma tênue recuperação da lavoura como espaço de produção da cultura gauchesca, esta há muito tempo tomada como exclusividade simbólica da grande propriedade pecuária. Na apresentação desse texto, nosso escritor questiona o que considera o grande tabu da literatura regionalista do estado: "não se concebe história que fuja às lides pastoris"; "Conto que, deixando o cenário das estâncias de criação de gado, penetre nas fazendas de agricultura, poderá ser 'brasileiro' mas jamais 'rio-grandense'" (BARBOSA LESSA 1958, p. 45). A argumentação do autor recorre à história da região, já que sua primeira grande força econômica teria sido a proveniente das plantações de trigo dos imigrantes açorianos. Mesmo depois de a peste da "ferrugem" ter dizimado tais lavouras, "gerações inteiras de 'rio-grandenses pêlo duro' continuaram estoicamente dedicados ao cultivo da terra".

Outrossim, o texto incorpora a contribuição negra à formação do sul-rio-grandense. A crítica se volta novamente para a historiografia, que teria transformado como "idéia feita", "sem que pesquisas mais acuradas tivessem dado veredicto final", a posição de que a escravidão havia sido inexpressiva no sul do país. Os "causos" de escravidão, mantidos pela tradição popular, não possuiriam, assim, legitimidade para ocupar as páginas da literatura. Barbosa Lessa recorre, então, ao trabalho do historiador Jorge Salis Goulart ${ }^{20}$ para mostrar

\footnotetext{
${ }_{19}$ Como mostrado por Mara Rodrigues (2006) no caso de Moysés Vellinho, a literatura poderia servir, inclusive, como porta de entrada para a crítica histórica.

${ }^{20}$ A obra citada é o livro A formação do Rio Grande do Sul, publicado em 1927. Cabe lembrar que este autor é conhecido como um dos construtores do mito da democracia racial no Rio Grande do Sul. O uso que Lessa faz de seu texto é, entretanto, meramente probatório, para indicar a presença negra, negada por grande parte da historiografia tradicional. Como veremos nas próximas linhas, Barbosa Lessa centra sua narrativa justamente no conflito entre escravos e escravistas.
} 
que as zonas de intensa agricultura e os centros de fabricação de charque, como Pelotas e Porto Alegre, pela natureza dessas indústrias, exigiam numerosa escravaria, "a qual vergava ao peso dos mais árduos trabalhos" (BARBOSA LESSA 1958, p. 46). O conto narra a valentia do escravo que domou o selvagem potro "Cabos Negros", utilizado para castigar os rebeldes: "O negro fujão, reconduzido à estância, era arrojado aos pés de Don Pepe para optar entre a dor e o medo. - O que escolhes, crioulo? A estaca ou Cabos Negros?" (BARBOSA LESSA 1958, p. 48). Todos preferiam o açoite na estaca a enfrentar o perigoso cavalo. Para salvar a vida de Pai Núncio, que fora pego pelo feitor da fazenda ao tentar trazer João Batista de volta da sua fuga e evitar o confronto com o potro, esse último decide matar Cabos Negros. Da luta nasce uma surpreendente amizade, e o escravo ganha a liberdade no lombo do cavalo, longe das terras do Sinhô, "num só corpo, ao feitio dos centauros" (BARBOSA LESSA 1958, p. 67). A imagem é significativa, uma vez que "centauro" é um dos termos utilizados desde o romantismo oitocentista para designar o cavaleiro sulino. Na versão dominante de memória, ele era o militar estancieiro. Logo, a metáfora se tornava quase exclusividade branca.

Em outra frente, Barbosa Lessa daria atenção ao papel da mulher em seu escrutínio literário do Rio Grande. Como vimos, um dos contos tem como narradora e protagonista uma personagem feminina. Seu primeiro romance, Os Guaxos, ${ }^{21}$ publicado em 1959, escolhido melhor romance do ano pela Academia Brasileira de Letras, desenvolvia a questão. ${ }^{22}$ Chama a atenção o fato de que a primeira edição condensada (a $3^{a}$ ) do livro, publicada em 1984, recebeu o expressivo subtítulo de "o romance do gaúcho a cavalo e da mulher de estância". ${ }^{23}$ Mesmo que Barbosa Lessa construa seus personagens seguindo um modelo andro-heterocentrado, em que o binômio masculino/feminino estruturador da lógica narrativa continua reservando ao primeiro polo os privilégios da diferença, encontramos também certa flexibilização dos padrões de feminilidade tradicional. As personagens femininas mais relevantes, Celita, Sia Bela, Zefinha e Ruana, encarnam diferentes papéis que, grosso modo, ocupam lugares distintos numa escala valorativa entre dois modelos de ser mulher: a "mulher guaxa", com sina de china (companheira do gaúcho vago do passado fronteiriço), e a "mulher prendada", esposa e mãe. O segundo é o ideal, a regra, o desejado; o primeiro é mais do que marginal, é o do ostracismo social. Em ambos os casos limite, a mulher gaúcha é o "elemento passivo - como a terra - a quem não cabe uma palavra de queixume ou gesto de revolta". É a sina de todas: "Se assim é, foi porque o destino quis" (BARBOSA LESSA 1959, p. 118). No entanto, as constatações acabam por se revelar grandes críticas à condição

\footnotetext{
${ }^{21}$ A palavra "guaxo" designa o terneiro criado sem o leite materno, ou seja, denomina metaforicamente o "desgarrado", indivíduo sem raízes e sem paradeiro fixo.

$22 \mathrm{O}$ texto foi bem recebido pela crítica do estado e do centro do país. Em Porto Alegre, por exemplo, Aldo Obino o saudava como "romance enxuto, áspero e de paixão". Walter Spalding o elegia como o "melhor e maior romance do Rio Grande até hoje aparecido". No Rio de Janeiro, Antonio Olinto o caracterizava como "romance bem realizado". Em São Paulo, Sérgio Milliet recomendava sua leitura "sem medo de errar" e afirmava que nosso autor havia conquistado "lugar de honra entre os romancistas nacionais".

${ }^{23}$ A quinta e última edição, publicada pela Editora Alcance em 2002 por meio de convênio com a COPESUL, carrega apenas o epíteto de "romance do gaúcho a cavalo".
} 
de subordinação, deixando brechas para outra interpretação: "Mas esta religião fatalista jamais impôs que os humanos se sentissem indefesos e, de antemão, derrotados. Cada um deve tirar e descobrir dentro de si a força que possui".24 As mulheres, assim, ao mesmo tempo em que são iguais, são também todas diferentes. Na diferença, elas podem encontrar sua força - no domínio das lidas domésticas, no domínio do amor ou no domínio da vida -, mas é na igualdade que brota a força específica de cada uma delas. Tia Velha, por exemplo, é temida por todos, pois faz mandingas, benzeduras, cura doenças, protege as plantas e, se quiser, cria paixões: "E os homens todos, na estância, sabem que Tia Velha, a velha escrava, um traste, tem mais força que eles próprios. Tem força porque é mulher. Mexe os cordões do Destino. Só as mulheres tem tal força" (BARBOSA LESSA 1958, p. 118).

A valorização de sujeitos históricos pouco lembrados pelas narrativas oficiais tem um último contraponto, não menos importante: a reafirmação do caráter popular do gaúcho histórico. A posição parece óbvia para um folclorista e literato filiado à tradição gauchesca. Contudo, Barbosa Lessa olhava mais para frente do que para trás, se dirigindo a dois campos de produção letrada: fora da literatura, como temos visto, contra o gaúcho elitizado da memória histórica dominante no IHGRS; dentro do gênero gauchesco, contra a declaração de morte do gaúcho a cavalo.

Seguindo a linha de Cyro Martins, ${ }^{25}$ Ivan Pedro de Martins denunciou o pauperismo do homem do campo no Rio Grande do Sul em seus livros Fronteira agreste (1944) e Caminhos do sul (1946). Em 1955, num momento próximo à estreia de Barbosa Lessa na ficção, tal escritor publicou um livro de contos intitulado Do campo e da cidade. A seleção de histórias curtas escritas ao longo de 18 anos pretendia dar conta das pobrezas rural e urbana, de conflitos entre campo e cidade, entre peão e patrão, pobre e rico. Para Antônio Hohlfeldt:

A contribuição de Ivan Pedro de Martins consiste na abordagem explícita da vida dos homens marginalizados dessa sociedade, a partir dos próprios espaços físicos e geográficos que ocupam, evidenciando que também a localização dos povos não é nem gratuita nem destituída de sentido (HOHLFELDT 1998, p. 19).

No conto intitulado "Tapera", a degeneração do ambiente se confunde com a pobreza dos personagens principais: "O capim, o mato, as embaúbas esguias, o sapé amarelado, as tiriricas deselegantes, tudo parece morto por excesso de seiva" (MARTINS 2000, p. 27). A lida de tropeiro é o objeto do primeiro texto. A vida descrita é dura, destituída de qualquer encanto, em nada lembrando a figura há alguns anos celebrada por Barbosa Lessa. O personagem que cede o

\footnotetext{
24 "Lina Peixoto alimentou em seu ventre o filho que Ihe trouxe a redenção. Sia Bela alimentou em seu rancho a filha com que voltou à casa-grande. Ruana alimenta em seu corpo feitiços que os homens temem. E se Zefinha não possui tais feitiços pode porém apelar às artes de Tia Velha" (BARBOSA LESSA 1959, p. 118).

25 Juntamente com Pedro Wayne e Aureliano de Figueiredo Pinto, segundo Regina Zilberman, tais autores ilustram a perspectiva da produção literária regionalista sul-rio-grandense que marcou as décadas de trinta e quarenta: "Recuperam, pois, os aspectos característicos do regionalismo, porém despem-no de seu ufanismo gauchesco, sepultando a índole festiva em troca da expressão da desigualdade social" (ZILBERMAN 1980, p. 68).
} 
nome ao conto, Mané, de doze anos, é quem questiona a exploração, na crítica da resignação do companheiro de tropeada: "Inhô na cidade é outro homem. Patrão tá longe, ele conta vantaje. Home devia sê home em toda parte. Si Inhô quisesse derrubava o patrão de um soco só... e fica quieto quando o veio passa pito" (MARTINS 2000, p. 17). A faina na estância também passa ao largo das "festas de marcação" relatadas pelo jovem Lessa. Em "Sina", o Maneco se torna peão por necessidade e, talvez, por falta de alternativas: "A infância igual à de todos os filhos de pobres. Botando vacas, trazendo a cavalhada do piquete, enchendo mate para o patrão velho, mandalete das moças da casa, até os dezesseis anos o encontraram estreando numa esquila" (MARTINS 2000, p. 44).

Os dois livros de ficção compostos por Lessa no período também discutem, portanto, questões própias ao gênero gauchesco na literatura, traçando alternativas narrativas, estéticas e políticas à geração regionalista "realista" que dominava a produção local. A denúncia da pobreza e da morte do gaúcho também ganhariam as novas páginas de Barbosa Lessa. O último conto, intitulado "Papai Noel conta um causo", narra a triste história de um peão que, sem trabalho no campo, incorpora-se às filas de desempregados na cidade. Na noite de Natal, o velho senhor aceita se vestir de Papai Noel em troca de um prato de comida e de alguns trocados. Na apresentação do texto, nosso autor relata resumidamente o processo pelo qual o Rio Grande da pecuária se moderniza e se transforma, cedendo espaço à agricultura e gerando o êxodo rural. Com a introdução dos arados pelos colonos alemães e italianos e com os cercamentos das terrras, "Fazendas de criação, que antes necessitavam de dezenas de empregados, agora podiam prover às suas necessidades com meia dúzia de peões" (BARBOSA LESSA 1958, p. 167). Disfarçando uma lágrima, o velho peão termina seu relato de vida com uma prece a Papai Noel:

$\mathrm{Tu}$, que todos os anos vens visitar as cidades, por que te esqueceste dos campos?... Será que a luz do progresso fez os teus olhos cegar? Fez os teus olhos não ver que ali atrás das coxilhas hai muita gente que espera um presente de Natal?... Hai muito piá sonhando com um petiço pra montar... Hai muita chinoca linda que não tem água-de-cheiro pra esperar o namorado. Hai muito gaúcho velho que não tem no seu ranchito o pão que traz a alegria, a luz que dá a inteligência. Papai Noel... Por que é que te esqueceste dos campos do meu Rio Grande?... (BARBOSA LESSA 1958, p. 178).

Dessa forma, Barbosa Lessa aliava um canto de luto à crítica social, utilizando o mito do gaúcho pampiano como fonte para a denúncia, mas também, diferentemente dos regionalistas "disfóricos", como modelo para a redenção do Rio Grande: "Escuta, Papai Noel... De outra vez que tu voltares, traz - é o que eu te peço, meu Santo! - traz consigo mil cavalos pra espalhar nos rancherios. Pois já existe, neste pago, gaúchos sem nazarenas... sem esporas... sem querência..." (BARBOSA LESSA 1958, p. 178). 


\section{Conclusões}

O projeto ficional de Barbosa Lessa é tributário de seus projetos de memória e de folclore, mas não no sentido de transposição direta de perspectiva de uma frente de produção a outra. O caso da representação do feminino é exemplar dessa constatação. Se nas danças tradicionais, ${ }^{26}$ no aparato visual (vestimentas, adereços, gestual) e na categoria de "prenda", ${ }^{27}$ inventada para comportar a mulher tradicionalista e desviar dela a suspeita que pesava sobre a china do passado gaúcho, destaca-se um modelo patriarcal bastante rígido, na literatura de imaginação, ao contrário, há espaço para ambiguidades, oscilações, para a manifestação de padrões feminininos marginais, a valorização da mulher como um todo e uma sutil denúncia da submissão, culturalmente construída. A ficção deve ao folclore na medida em que este apresenta àquela uma matéria bruta para a estetização: motivos, personagens, estratégias narrativas, fórmulas. Mas sua lapidação é sempre criativa, comprometida com o literário e dirigida a frentes de debate mais atuais, com novas oportunidades para a reflexão. O confronto dos textos com os contextos discursivos mais amplos revelaram, assim, uma ambição ficcional de tipo moderno: o literato explica a realidade pela ficção. A representação não é subalterna ao real. A autonomia do literário é mais do que textual, é cognitiva. A ficção objetiva produzir um saber sobre o mundo "sem postular que esse saber tenha uma natureza superior e irredutível àquele das Ciências Sociais" (ANHEIM; LILTI 2010, p. 255, tradução nossa). ${ }^{28}$

O caso Sepé exigiu de Barbosa Lessa a reflexão não somente sobre o passado missioneiro, mas, principalmente, sobre o estado do debate historiográfico no Rio Grande do Sul. A sua tomada de posição Ihe permitiu a organização do projeto ficcional nascente para atender a demandas de memória que o autor considerava reprimidas. Evidentemente, a avaliação exigia o reconhecimento da vida social: a exclusão na memória histórica estava vinculada à condição das massas subalternas e de atores sociais marginalizados. A confiança na ficção como explicação tinha como reverso a aposta em seu poder de mobilização. Para solucionar problemas da estrutura social, era necessário transformar o universo simbólico.

Ao tratar da distinção entre biografia histórica e biografia literária no século XIX, Philippe Levillain chegou à seguinte constatação: "Quando a Literatura recorre à História, esta pode desempenhar o papel de simples suporte, como a parede para o afresco, se se trata de um romance, como a tela para o retrato, se se trata de uma biografia" (LEVILLAIN 2003, p. 154). A obra de Barbosa Lessa demonstra uma mudança radical na função do literário, mesmo que construída

\footnotetext{
${ }^{26}$ Barbosa Lessa e Paixão Côrtes são os criadores das coreografias que ainda hoje se apresentam nos CTG. As danças tradicionais são composições inspiradas em pesquisa folclórica, como dito. Além do Manual, de 1956, foram divulgadas num LP gravado por Inezita Barroso.

27 O termo não foi historicamente utilizado como denominação da mulher gaúcha. Tratou-se de uma escolha do movimento tradicionalista baseada em dois antecedentes. "Prenda", no vocabulário rural, significava objeto de valor. Somava-se a isso a existência, no parco repertório folclórico sobre o "gaúcho", a música Prenda minha, registrada por Carlos Von Koseritz, no final do século XIX e reproduzida por Mário de Andrade em seu Ensaio sobre a música brasileira, na qual um campeiro se referia à amada como seu bem valioso. $O$ termo denota claramente a posição de objeto da mulher e sua posse pelo homem.

${ }^{28}$ No original: "[...] sans postuler que ce savoir soit d'une nature supérieure et irréductible à celui des sciences sociales".
} 
na já longa duração da história (e da historiografia literária) pós-romantismo. ${ }^{29}$ Quando a literatura fala à história, já não há hierarquia entre suportes e mensagens; a ficção disputa a representação do passado, pois conhece seus usos políticos.

\section{Referências bibliográficas}

A CONQUISTA das Missões. Correio do Povo. 14 jan. 1956, p. 8.

ANHEIM, Étienne; LILTI, Antoine. Savoirs de la littérature: introduction. Annalles HSS, n. 2, p. 253-260, 2010.

BARBOSA LESSA, Luiz Carlos. História do chimarrão. $3^{a}$ edição. Sulina: Porto Alegre, 1986 [1953]. $112 \mathrm{p}$.

. O boi das aspas de ouro. Porto Alegre: Globo, 1958. 196 p.

. Os guaxos. São Paulo: Livraria Francisco Alves, 1959. 354 p.

Segundo centenário de Tiarajú. Pasta 20.1, fevereiro de 1956. Manuscrito. ACERVO BARBOSA LESSA.

BERNARDI, Mansueto. O primeiro caudilho rio-grandense: fisionomia do herói missioneiro Sepé Tiaraju. Porto Alegre: EST/Sulina, 1980. 172 p.

BITTENCOURT, Gilda Neves da Silva. O conto sul-rio-grandense: tradição e modernidade. Porto Alegre: Editora da UFRGS, 1999. 254 p.

CASTRO, Julio Sergio de. Canto a Sepé. Correio do Povo, 23 nov. 1957, p. 8.

CORADINI, Odaci Luiz. As missões da "cultura" e da "política": confrontos e reconversões de elites culturais e políticas no Rio Grande do Sul (19201960). Estudos Históricos, Rio de Janeiro, n. 32, p. 125-144, 2003.

FERREIRA FILHO, Arthur. Caudilho, não. Correio do Povo, 02 nov. 1957, p. 13.

FIGUEIREDO, Joana Bosak de. A tradução da tradição: gaúchos, guaxos e sombras: o regionalismo revisitado de Luiz Carlos Barbosa Lessa e de Ricardo Güiraldes. 200 p. Tese (Doutorado em Letras). Programa de PósGraduação em Letras, Instituto de Letras, Universidade Federal do Rio Grande do Sul, Porto Alegre, 2006.

GAMA, José Basílio da. O Uraguai. Porto Alegre: L\&PM, 2009 [1769], 144 p.

GUTFREIND, Ieda. A historiografia rio-grandense. Porto Alegre: Editora da UFRGS, 1992, $217 \mathrm{p}$.

JAEGER, Luiz Gonzaga. Refutação da Comissão de História. In: BERNARDI, Mansueto. O primeiro caudilho rio-grandense: fisionomia do herói missioneiro Sepé Tiaraju. Porto Alegre: EST/Sulina, 1980, p. 146-155.

\footnotetext{
${ }^{29}$ Não se trata aqui de atestar uma singularidade lessiana, mas de apontar para uma reorientação, em relação ao século XIX, nos usos da ficção que sua obra compartilha. Essa interpretação também não é nova, mas diante das discussões recentes em historiografia sobre o potencial cognitivo da literatura de imaginação, este é um ponto que vale a pena lembrar. Para mais exemplos e análises pormenorizadas de teses históricas sustentadas na literatura rio-grandense, ver também RODRIGUES 2006.
} 
LEVILLAIN, Philippe. Os protagonistas: da biografia. In: RÉMOND, René (org.). Por uma história política. $2^{\text {a }}$ edição. Rio de Janeiro: FGV Editora, 2002, p. 141-184.

LESSA, Luiz Carlos. Tropeiros. Revista do Globo, Porto Alegre, p. 28-31, 6263, 10 maio 1947.

LIMA, Afonso Guerreiro; ROSA, Othelo; VELLINHO, Moysés. Parecer da Comissão de História do Instituto Histórico e Geográfico do Rio Grande do Sul Contra Sepé Tiaraju. In: BERNARDI, Mansueto. O primeiro caudilho riograndense: fisionomia do herói missioneiro Sepé Tiaraju. Porto Alegre: EST/Sulina, 1980, p. 139-142.

LOPES NETO, João Simões. O lunar de Sepé. In: Lendas do Sul. São Paulo: Globo, 1996 [1913], p. 101-107.

MARTINS, Cyro. Visão crítica do regionalismo. In:

Sem rumo. $4^{a}$ edição. Porto Alegre: Movimento, 1979.

MARTINS, Ivan Pedro de. Do campo e da cidade. Porto Alegre: Movimento, 2000. $152 \mathrm{p}$.

NEDEL, Letícia Borges. Paisagens da Província: o regionalismo sul-riograndense e o Museu Júlio de Castilhos nos anos cinqüenta. Dissertação (Mestrado em História Social). 335 p. Programa de Pós-Graduação em História Social, Instituto de Filosofia e Ciência Sociais, Universidade Federal do Rio de Janeiro, Rio de Janeiro, 1999.

. Regionalismo, historiografia e memória: Sepé Tiaraju em dois tempos. Anos 90, Porto Alegre, v. 11, n. 19/20, p. 347-389, 2004.

. Um passado novo para uma História em crise: regionalismo e folcloristas no Rio Grande do Sul. 560 p. Tese (Doutorado em História). Instituto de Ciências Humanas, Programa de Pós-Graduação em História, Universidade de Brasília, Brasília, 2005.

O 35. Boletim Mensal do "35" Centro de Tradições Gaúchas. Ano I Setembro de 1950.

PESAVENTO, Sandra Jatahy. Narrativas cruzadas: história, literatura e mito: Sepé Tiaraju das Missões. In: (org.). Sepé Tiaraju: muito além da lenda. Porto Alegre: Comunicação Impressa, 2006, p. 31-49.

RODRIGUES, Eurico. Variações sobre as missões, Tiaraju e Languiru. Correio do Povo, 09 nov. 1957, p. 9.

RODRIGUES, Mara Cristina de Matos. Da crítica à História: Moysés Vellinho e a trama entre a província e a nação. 243 p. Tese (Doutorado em História). Programa de Pós-Graduação em História, Instituto de Filosofia e Ciências Humanas, Universidade Federal do Rio Grande do Sul, Porto Alegre, 2006.

ZILBERMAN, Regina. A literatura no Rio Grande do Sul. Porto Alegre: Mercado Aberto, 1980, $168 \mathrm{p}$. 